\title{
Are there symplastic connections between the endosperm and embryo in some angiosperms? - a lesson from the Crassulaceae family
}

\author{
Małgorzata Kozieradzka-Kiszkurno • \\ Bartosz Jan Plachno
}

Received: 30 September 2011 / Accepted: 9 November 2011 / Published online: 27 November 2011

(C) The Author(s) 2011. This article is published with open access at Springerlink.com

\begin{abstract}
It is believed that there is symplastic isolation between the embryo (new sporophyte) and the endosperm (maternal-parental origin tissue, which nourishes the embryo) in angiosperms. However, in embryological literature there are rare examples in which plasmodesmata between the embryo suspensor and endosperm cells have been recorded (three species from Fabaceae). This study was undertaken in order to test the hypothesis that plasmodesmata between the embryo suspensor and the endosperm are not so rare but also occur in other angiosperm families; in order to check this, we used the Crassulaceae family because embryogenesis in Crassulaceae has been studied extensively at an ultrastructure level recently and also we tread members of this family as model for suspensor physiology and function studies. These plasmodesmata even occurred between the basal cell of the two-celled proembryo and endosperm cells. The plasmodesmata were simple at this stage of development. During the development of the embryo proper and the suspensor, the structure of plasmodesmata changes. They were branched and connected with electron-dense material. Our results suggest that in Crassulaceae with plasmodesmata between the endosperm and suspensor, symplastic connectivity at this
\end{abstract}

Handling Editor: Hanns H. Kassemeyer

M. Kozieradzka-Kiszkurno $(\bowtie)$

Department of Plant Cytology and Embryology,

University of Gdańsk,

Kładki 24 St,

80-822 Gdańsk, Poland

e-mail: stokrota@biotech.ug.gda.pl

B. J. Płachno

Department of Plant Cytology and Embryology,

Jagiellonian University,

Grodzka 52 St,

31-044 Cracow, Poland cell-cell boundary is still reduced or blocked at a very early stage of embryo development (before the globular stage). The occurrence of plasmodesmata between the embryo suspensor and endosperm cells suggests possible symplastic transport between these different organs, at least at a very early stage of embryo development. However, whether this transport actually occurs needs to be proven experimentally. A broader analysis of plants from various families would show whether the occurrence of plasmodesmata between the embryo suspensor and the endosperm are typical embryological characteristics and if this is useful in discussions about angiosperm systematic and evolution.

Keywords Crassulaceae - Embryo suspensor - Endosperm · Plasmodesmata - Symplastic transport - Ultrastructure

\section{Introduction}

Plant cells communicate with each other via channels called plasmodesmata (PD). PD are not passive channels, but are critical players in gene regulation, controlling the intercellular transport of macromolecules between particular cells during development (e.g. Zambryski and Crawford 2000; Zambryski 2004; Xu and Jackson 2010; Hyun et al. 2011; Niehl and Heinlein 2011). Two possible pathways are involved in the entrance of water and nutrients to a plant: one is the symplastic pathway that is known to pass through the plasmodesmata and the other is the apoplastic pathway that traverses the cell wall and intercellular air spaces in plant tissues without crossing the cytoplasm.

The sporophytic generation of angiosperms is initiated by a double fertilisation event that results in the formation of a single-celled zygote and a progenitor of the endosperm. The zygote is a unicellular system that through a 
programmed sequence of events gives rise to a multicellular embryo with well-differentiated organs (Natesh and Rau 1984; Raghavan 2006). Studies in recent years have shown that during the important phases of sexual reproduction, a restriction or inhibition of symplastic communication may be crucial in the processes of cell differentiation, which require the inclusion of an individual development programme (Ding et al. 1999; Zambryski and Crawford 2000; Pfluger and Zambryski 2001; Ingram 2010). Symplastic isolation takes place at the beginning of the sporophytic generation. This isolation appears at the zygote level. After fertilisation, the angiosperm zygote must begin a new programme of sporophyte development based on the diploid genotype established at the time of gamete fusion. In several species of Rhododendron and in Ledum groenlandicum, a callose wall around the zygote appears within approximately the first $2 \mathrm{~h}$ after fertilisation. According to Williams et al. (1984), a special callose wall may function to preserve the genetic isolation of this cell from the maternal and endosperm tissues of a different genotype during the initiation of the new sporophyte development phase.

It is characteristic of the embryogenesis of many angiosperms that the early embryo differentiates into two parts: the embryo proper and the suspensor, which develops rapidly and is short-lived. In most cases, the suspensor functions early in embryogenesis and then degenerates during the later stages of development and is not present in the mature seed (Maheshwari 1950; Yeung and Meinke 1993; Schwartz et al. 1997; Lee et al. 2006; Zhukova 2006; Kozieradzka-Kiszkurno et al. 2010). This organ pushes the embryo proper into the endosperm cavity and connects the embryo proper to the surrounding maternal and endosperm tissues, thus serving as a conduit for the nutrients and growth regulators required for embryonic development (Yeung and Meinke 1993; Raghavan 2006; Kawashima and Goldberg 2010). Interaction between the embryo and surrounding endosperm has a role in determining the acquisition of metabolic competence (Raghavan 1997). Several ultrastructural studies have suggested that the embryo is symplastically isolated from the endosperm (Dute et al. 1989; Mansfield and Briarty 1991), but the stage at which symplastic isolation occurs has still not been clarified.

Symplastic communication via plasmodesmata is an important element in the system of information exchange between cells during plant growth and development (Jackson 2000; Kim and Zambryski 2005). The fluorescent tracers that characterise the pathway for symplastic transport in the suspensor cells of developing embryos has been demonstrated for a few plants, among others in Arabidopsis (Kim et al. 2002; Kurczyńska 2008) and Phaius tankervilliae (Lee and Yeung 2010). Studies of the role of symplastic communication during embryogenesis have been based on the analysis of the movement of fluorochromes or GFP between embryo cells at different stages of embryo development. It has been shown that the appearance of symplastic domains precedes the appearance of morphologically different structures during Arabidopsis embryogenesis. It appears that the Arabidopsis embryo is one symplastic domain until the mid-torpedo stage. From that moment of its development, the embryo is no longer a single symplast and the movement of symplastic transport tracers of different molecular weights is restricted to different symplastic domains and subdomains that correlate with the development of primary tissues (Kim et al. 2002).

The symplastic isolation between the embryo and the endosperm is quickly followed by the initiation of cuticle material on the outside of the embryo proper. Several studies have reported the deposition of a cuticle on the early globular embryo, and in some species, cuticular material is even detectable in the fertilised zygote (Bruck and Walker 1985; Chamberlin et al. 1994). In endosperm-embryo communication, the movement of small polar molecules across the apoplast cannot be ruled out. In most angiosperms, the role of the suspensor in metabolite transport is further underlined by the presence of numerous plasmodesmata linking the cells with each other and with the embryo proper, while at the same time plasmodesmata are absent from the outer walls of the embryo. However, plasmodesmata in the walls between the suspensor and the endosperm have only been reported in a few species of Fabaceae: Glycine (Dute et al. 1989), Medicago (Sangduen et al. 1983) and Vicia faba (Johansson and Walles 1993). Crassulaceae have been extensively investigated recently using morphological (Weng and KuongHuang 1998; Weryszko-Chmielewska and Chernetskyy 2005; Chernetskyy and Weryszko-Chmielewska 2008), ultrastructural (Kozieradzka-Kiszkurno et al. 2010, 2011a, b) and cytochemical techniques (Kozieradzka-Kiszkurno and Bohdanowicz 2006). In this family, the suspensor basal cell forms special haustorial protrusions that penetrate the ovular tissues and that are apparently the main source of nutritive substances for the embryo proper. The mature differentiated suspensor consists of a large basal cell and three to four chalazal cells. In Crassulaceae, the suspensor precedes the embryo proper as well as the endosperm in development (Kozieradzka-Kiszkurno and Bohdanowicz 2006; Kozieradzka-Kiszkurno et al. 2011a).

It should be emphasized that ovules are interesting models for study not only for symplastic and apoplastic transport but that there are also ovule characteristics that are important in discussions about angiosperm phylogeny and evolution (e.g. Endress 2005, 2011; Werner et al. 2011).

This paper extends the authors previously reported observations about the suspensor and includes new 
information about the presence and ultrastructural features of plasmodesmata between the embryo suspensor and the endosperm in Crassulaceae. In this study, we test the hypothesis that the plasmodesmata between the embryo suspensor and the endosperm are not so rare but are a feature which can occur in the other angiosperm families.

\section{Materials and methods}

Plant material

Plants of Sempervivum arachnoideum L. at different stages of development were obtained from a commercial company (http://kaktusiarnia.pl/index1.html) in northern Poland. Inflorescences of Jovibarba sobolifera (Sims) Opiz were collected from its natural habitat in Kokotek near Lubliniec in the south of Poland. Some additional plants of these species as well as Graptopetalum bellum L. were obtained from The Botanic Garden of the Jagiellonian University, Cracow, Poland. Sedum hispanicum L. and Sedum acre L. were collected from their natural habitats near Gdańsk, in the north of Poland.

\section{Methods}

For electron microscopy, the ovules at different stages of embryo development were fixed in $2.5 \%$ formaldehyde (prepared from paraformaldehyde) and $2.5 \%$ glutaraldehyde in a $0.05 \mathrm{M}$ cacodylate buffer $(\mathrm{pH}=7.0)$ for $4 \mathrm{~h}$ at room temperature. The material was subsequently rinsed in the same buffer and post-fixed in 1\% osmium tetroxide in a cacodylate buffer at $4^{\circ} \mathrm{C}$ overnight. Specimens were treated with $1 \%$ uranyl acetate in distilled water for $1 \mathrm{~h}$, dehydrated in a graded acetone series and embedded in Spurr's resin. Serial ultrathin (60-100 nm) sections were cut with a diamond knife on a SORVALL MT 2B microtome and then post-stained with a saturated solution of uranyl acetate in $50 \%$ ethanol and with $0.04 \%$ lead citrate. Observations were made using a Philips CM 100 transmission electron microscope operating at $80 \mathrm{kV}$. Sections for light microscopy were cut at $0.5-2 \mu \mathrm{m}$ with glass knives and stained with $0.05 \%$ toluidine blue 0 in $1 \%$ sodium tetraborate.

\section{Results}

In all of the species examined ( $G$. bellum, J. sobolifera, $S$. acre, $S$. hispanicum and $S$. arachnoideum), the embryo development is of the Caryophyllad type (Figs. 1 and 2). The first division of the zygote is transverse and asymmetrical. Two sister cells of differing sizes are formed: the basal

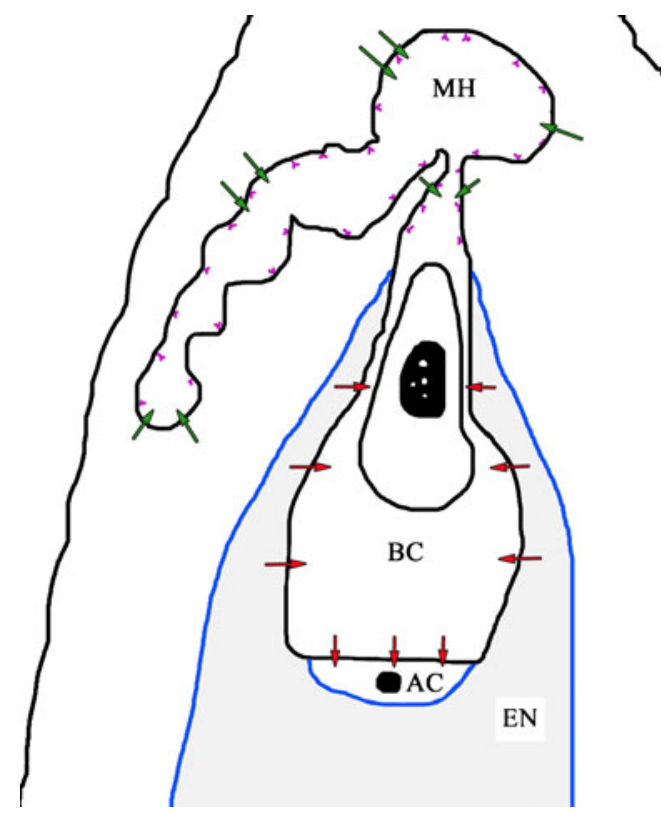

Fig. 1 Schematic longitudinal section from a two-celled proembryo showing different pathways for the apoplastic and symplastic transport of nutrients in the crassulacean ovule: $B C$ basal cell, $A C$ apical cell, $E N$ endosperm, $M H$ micropylar haustorium; violet line wall ingrowths, blue line cuticle. Arrows nutrient transport route, red symplastic transport, green apoplastic transport

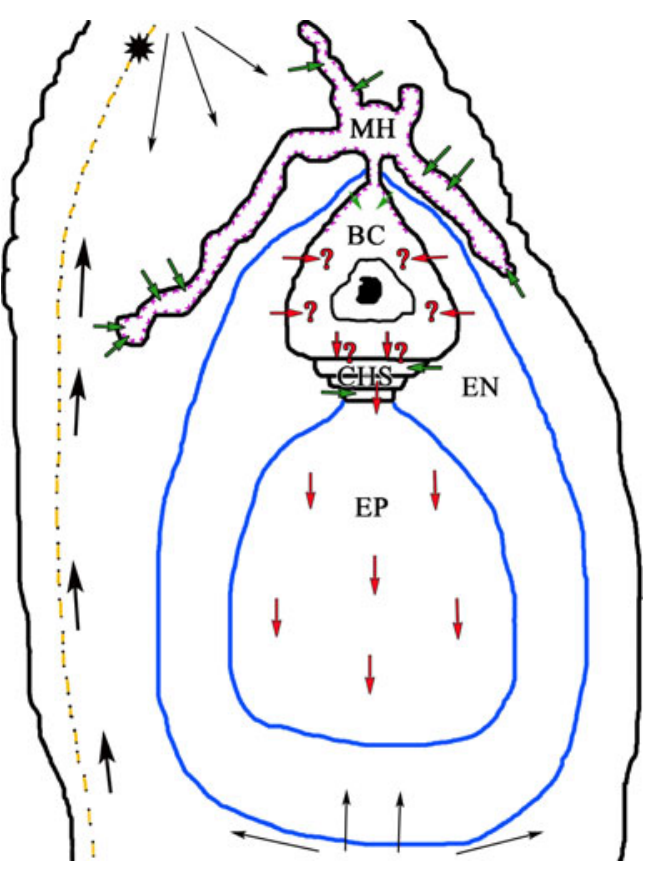

Fig. 2 Schematic longitudinal section showing different pathways for the apoplastic and symplastic transport of nutrients in the crassulacean ovule: $B C$ basal cell, $C H S$ chalazal suspensor cells, $E N$ endosperm, $E P$ embryo proper, $M H$ micropylar haustorium; violet line wall ingrowths, blue line cuticle, star vascular bundle. Arrows nutrient transport route, red symplastic transport, green apoplastic transport, thick black arrows transport of metabolites and water through by the vascular bundle in the funiculus, thin arrows transport of metabolites through the chalaza 
cell and the apical cell (Fig. 1). The basal (micropylar) cell is larger and vacuolated while the apical (chalazal) cell is smaller and densely cytoplasmic. The cells are connected by simple plasmodesmata. There are also numerous plasmodesmata between the suspensor basal cell and the endosperm cells. At this stage of development, the plasmodesmata are simple (Fig. 3a, b). In contrast to the basal cell, the apical cell of the proembryo is devoid of plasmodesmal connections with the endosperm. The basal cell undergoes no division, becomes much enlarged and forms a basal suspensor cell. The basal cell produces haustorial branches that invade the micropyle and adjacent tissues. The apical cell divides several times and develops into the embryo proper and the chalazal suspensor. Differentiation of the basal cell begins shortly after the division.

The presence of plasmodesmata in the wall between the basal cell and the endosperm and ultrastructural changes in them were investigated and compared with the development of the embryo proper.

\section{S. acre and S. hispanicum}

When the embryo proper reaches the globular stage of development, plasmodesmata are also observed in the wall between the basal cell and the endosperm cells. They are branched and at the ultrastructural level their plasmodesmata are very similar to the plasmodesmata that were reported from the border between the basal cell of the suspensor and the chalazal suspensor cells (KozieradzkaKiszkurno and Bohdanowicz 2006; Kozieradzka-Kiszkurno et al. 2011b). An electron-dense dome associated with the plasmodesmata on the basal cell side is shown in Fig. 3c. Shadows can be observed in these domes. The shadows show continuity with the profiles of the endoplasmic reticulum (Fig. 3d, e). There are also numerous simple plasmodesmata in the inner walls of the endosperm (Fig. 3c, e). When the embryo proper reaches the heart stage of development, the plasmodesmata are pronouncedly branched (Fig. 3d, e).
Fig. 3 Plasmodesmata between the basal cell $(B C)$ and the endosperm cells $(E N)$ in $S$. hispanicum L. (a-d) and $S$. acre L. (e); (a-e) electron micrographs. a-b Sections from a two-celled proembryo. a The wall $(W)$ between the basal cell $(B C)$ and the endosperm $(E N)$ of the proembryo. Scale bar $=$ $250 \mathrm{~nm}$. b Plasmodesmata from a at a higher magnification. Cytoplasm of the endosperm appears denser than that of the basal cell. Scale bar $=250 \mathrm{~nm}$. c Section from the globular stage embryo. Note

the unusual electron-dense material associated with the plasmodesma (arrows) on the basal cell $(B C)$ side. Unbranched plasmodesmata (red ring) are visible in the transverse walls $(W)$ of the endosperm $(E N)$. Scale bar $=$ $1 \mu \mathrm{m}$. d-e Sections from the heart stage embryo. Branched plasmodesmata with electron-dense material at a higher magnification; basal cell $(B C)$, endosperm $(E N)$, wall (W). Scale bar $=500 \mathrm{~nm}$
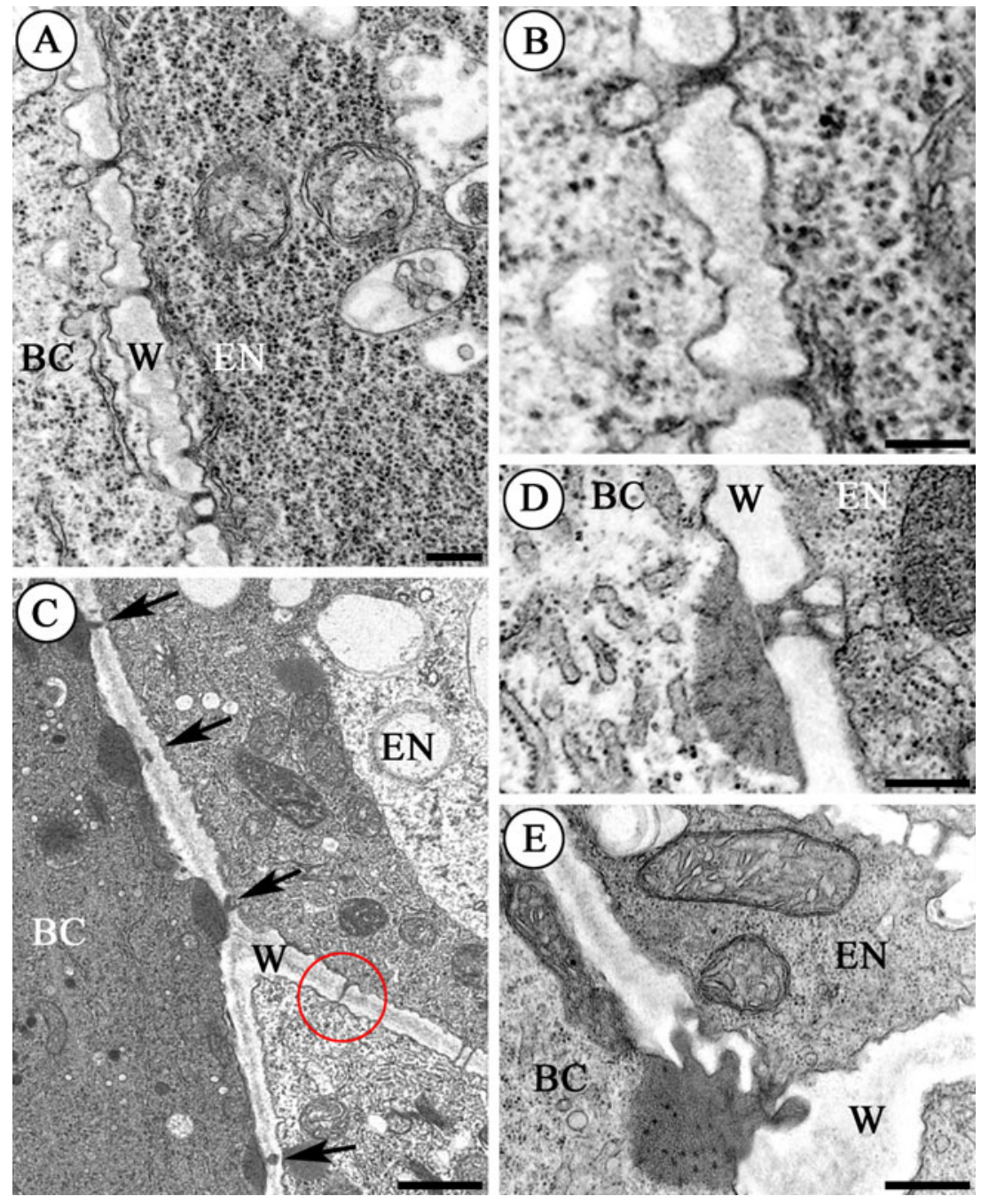
In all of the stages of development, the chalazal suspensor cells are devoid of plasmodesmal connections with the endosperm. There are no plasmodesmata in the outer walls of the whole embryo, but they are numerous in the inner walls of the embryo proper.

\section{G. bellum}

The fully differentiated suspensor (in the globular stage embryo) encompasses a large, pearl-shaped basal cell with a micropylar haustorium and a few chalazal cells. The micropylar part of the basal cell wall forms ingrowths. The most prominent organelle within the cell is the nucleus (Fig. 4a). There is a difference in the density of the cytoplasm of the basal cell and the endosperm cells (Fig. 4a, b). The wall between the suspensor basal cell and the endosperm cells is perforated by numerous compound plasmodesmata with electron-dense material on the basal cell side (Fig. 4b). These plasmodesmata are mostly unbranched (Fig. 4c) and are only rarely branched in the heart-stage embryo (Fig. 4d). There are numerous unbranched plasmodesmata in the inner walls of the endosperm (Fig. 4b, c) similar to Sedum. An electrondense dome associated with the plasmodesmata on the basal cell side has a very clear continuity with profiles of the endoplasmic reticulum (Fig. 4d). These plasmodesmata also resemble those in the wall between the basal cell and the chalazal cell in this species.

\section{J. sobolifera and S. arachnoideum}

No major differences were found between these genera and so they are treated together. Transfer wall ingrowths form in the wall that separates the suspensor basal cell from the endosperm cells. Numerous plasmodesmata with electrondense material are distributed between the ingrowths on the basal cell side of this wall (Fig. 5a). Compared to the previous species, these have strongly electron-dense material and are almost always simple. The continuity of the profiles of the endoplasmic reticulum in the electron-dense
Fig. 4 Plasmodesmata between the basal cell $(B C)$ and the endosperm cells $(E N)$ in $G$. bellum L. a semithin section, bd electron micrographs. a Semithin section (the globular stage embryo) showing a fragment of the large basal cell $(B C)$ bordered by the endosperm $(E N)$; nucleus $(N)$. The framed area is enlarged on $\mathbf{b}$. Scale bar $=10 \mu \mathrm{m}$. b Fragment of the wall $(W)$ between the basal cell $(B C)$ and the endosperm $(E N)$.

Note the electron-dense material associated with the plasmodesmata (arrows). Unbranched plasmodesmata are visible (red ring) between the transverse cells of endosperm $(E N)$. Scale bar $=1 \mu \mathrm{m}$. c Section from the globular stage embryo. Higher magnification of the wall $(W)$ separating the basal cell $(B C)$ from the endosperm cells $(E N)$. Note unbranched plasmodesmata between the endosperm cells (red rings). Scale bar $=1 \mu \mathrm{m}$. d Section from the heart stage embryo. Plasmodesma at a higher magnification. The electron-dense material has a continuity with the endoplasmic reticulum $(E R) ;(B C)$ basal cell, $(E N)$ endosperm, $(W)$ wall. Scale bar $=500 \mathrm{~nm}$

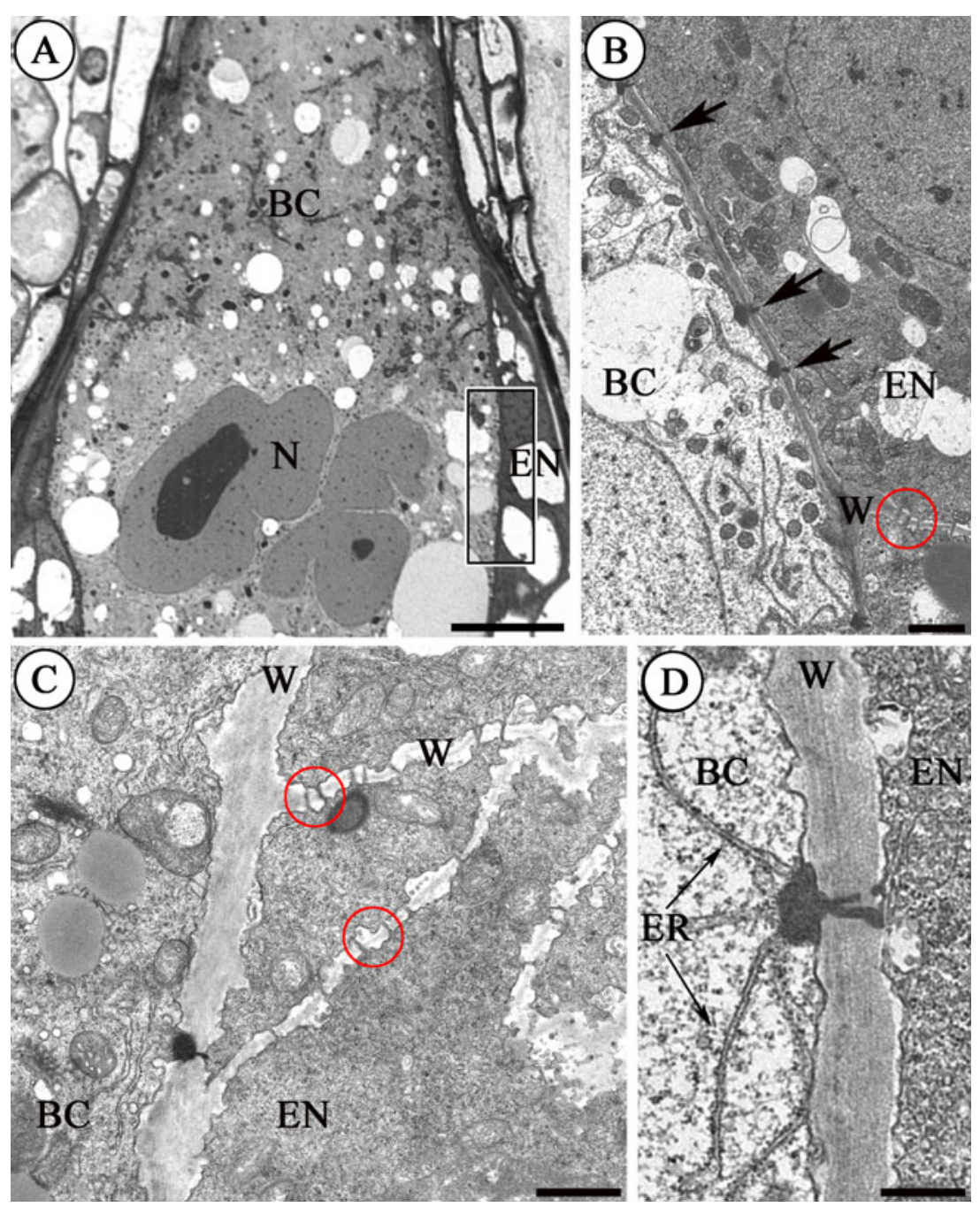




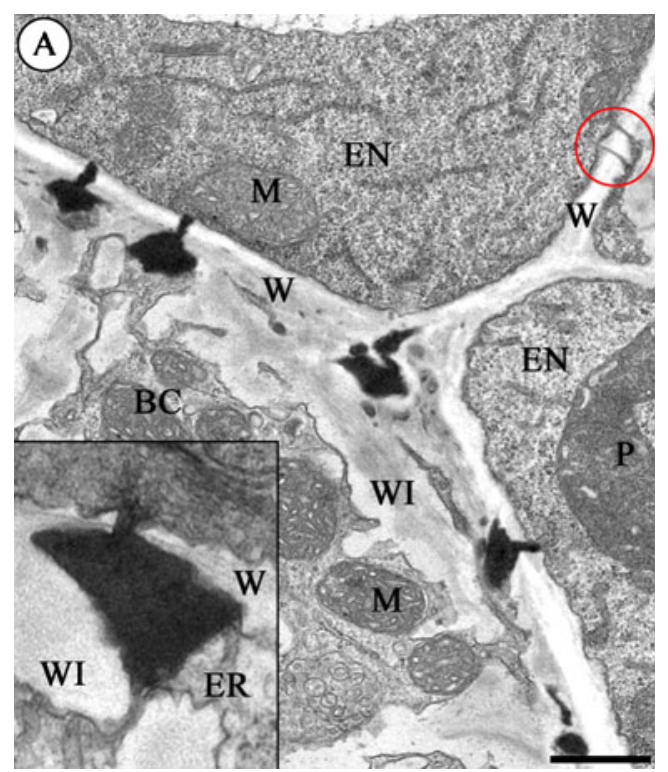

Fig. 5 a Part of the wall $(W)$ between the basal cell $(B C)$ and the endosperm ( $E N)$ in $S$. arachnoideum (late heart-stage embryo). Note the highly electron-dense material associated with the plasmodesmata; $(W I)$ wall ingrowths, $(M)$ mitochondrion, $(P)$ plastid. Scale bar= $500 \mathrm{~nm}$. Inset: Higher magnification of the plasmodesma in $J$. sobolifera; $(W)$ wall, $(W I)$ wall ingrowths, $(E R)$ endoplasmic reticulum

body is also preserved as in other species (Fig. 5a and inset). The chalazal suspensor cells and the embryo proper in all stages of development are devoid of plasmodesmal connections with the endosperm.

\section{Discussion}

The suspensor is a unique embryonic region that connects the embryo to the seed coat and is morphologically diverse throughout the plant kingdom in contrast to the embryo proper (Raghavan 2006; Kawashima and Goldberg 2010). This organ is the first differentiated structure that is produced during plant embryogenesis. Several studies have confirmed that it can serve as a channel for nutrient flow and may provide metabolites for the growth of the embryo proper (for a review, see Yeung and Meinke 1993).

Given the evolutionary and agronomic importance of angiosperm seeds, the complex combination of communication pathways that coordinate their growth and development remains remarkably poorly understood. The production of angiosperm seeds involves the coordinated growth and development of the maternally derived seed coat and the zygotic embryo and endosperm. Cell-cell communication and the delivery of nutrition through the selective establishment of symplastic and apoplastic barriers appear to play key roles in both pre- and post- fertilisation seed development (Ingram 2010).
In Crassulaceae, plasmodesmata were also observed in the walls between the suspensor basal cell and the endosperm. A similar distribution of plasmodesmata has been observed in the wall suspensors of a few species of Fabaceae: Glycine (Dute et al. 1989), Medicago (Sangduen et al. 1983) and V. faba (Johansson and Walles 1993). This paper is the first work that clearly shows that plasmodesmata between the suspensor and the endosperm are not rare and that also properly documents them. Johansson and Walles (1993) only wrote that plasmodesmata occurred between the endosperm and the embryo suspensor. Dute et al. (1989) and Sangduen et al. (1983) showed the plasmodesmata on the electron micrographs; however, neither described the structure and number of plasmodesmata between the embryo suspensor and the endosperm cells. Our documentation from electron microscopy shows that these plasmodesmata are not rare. In this study, electron micrographs from both of the above-mentioned papers were analysed, and it was found that those plasmodesmata are the simple type. Thus, those plasmodesmata are similar to the plasmodesmata in this study only in the early-stage embryo development of Crassulaceae. In the later stages of embryo development in the crassulacean species, the structure of plasmodesmata is complex. It should be emphasized that electron-dense material in the cytoplasm near plasmodesmata has also been described in Crassulaceae. Some other authors describe electron-dense material near the plasmodesmata in other tissues but the material occurred in the periplasmic space, e.g. in avocado (Botha and Cross 2000). Similar electron-dense material was noted by Rinne and van der Schoot (1998) in the tunica of the apical meristem of birch seedlings. Another example of the presence of osmiophilic material in the plasmodesmata is the glandular tissue of voodoo lily. It is likely that this material can also move to the neighbouring cells (Skubatz and Kunkel 1999). However, in Crassulaceae, this material is continuous during embryonic development. This osmiophilic material in the cytoplasm is near plasmodesmata, which may be callose, so it can be doubted whether plasmodesmata are functional.

There is little information available on metabolite transport in the developing ovule; however, there are now several approaches to the investigation of this transport mechanism. One technique relies on the use of dyes (Zhang and Zheng 1988; Werner et al. 2011) or radioactive elements (Coe 1954) to trace whether there is apoplastic or symplastic transport (Werner et al. 2011). Another approach is based on histochemical and immunochemical reactions (Willemse and Bednara 1979; Han et al. 2000). The placenta and ovary wall are the main sources of nutrients for an ovule. The chalaza is the first portion of the ovule to show the presence of nutrients since the vascular bundles end there in many taxa (also in Crassulaceae 
Fig. 2). Subsequently, the metabolites are transported to different reproductive and somatic tissues of the ovule via a system of specialised tissues (Shamrov 2000). Some investigations regarding embryo development in angiosperms have indicated the accumulation of cuticular materials on the surface of the embryo proper and their absence in the suspensor cell walls (Rodkiewicz et al. 1994; Yeung et al. 1996; Lee et al. 2006; Kozieradzka-Kiszkurno et al. 2011a; see also Fig. 2). Furthermore, the absence of cuticular substances in the suspensor would allow for apoplastic continuity between the maternal tissues and the embryo. The embryo and endosperm represent independent symplastic fields from a very early stage in embryogenesis. This has important implications in terms of both developmental signalling and nutrient uptake. The embryo must actively import all of its nutrients from the surrounding endosperm tissues and thus is completely reliant upon endosperm function. It can also be assumed that this new symplastic isolation may be extremely important in the process of differentiating the two structures, although this hypothesis remains untested (Ingram 2010). The way in which symplastically isolated cells communicate with their neighbours is virtually unknown.

Plant cells are connected via plasmodesmata, which are cytoplasmic channels that transverse plant cell walls. Plasmodesmata provide symplastic continuity between cells, thereby facilitating communication and allowing the coordination of growth and development. Plasmodesmata are plasma membrane-lined and have a core of modified endoplasmic reticulum (ER) in their centre (Oparka 2005; $\mathrm{Xu}$ and Jackson 2010; Faulkner and Maule 2011; Tilsner et al. 2011). Transport through plasmodesmata is believed to occur primarily through the cytoplasmic space between the plasma membrane and modified ER (Gunning and Steer 1975; Xu and Jackson 2010; Tilsner et al. 2011). Information concerning symplastic communication between the female gametophytic cells, however, is scarce and incomplete (Han et al. 2000). There is paradigm that there is symplastic continuity between the suspensor and the embryo proper (which is down-regulated at later stages of embryo development). However, the uptake of nutrients from the endosperm into the suspensor, the topic at hand, is viewed as apoplastic (e.g. Stadler et al. 2005; Kim et al. 2005; Lee and Yeung 2010). This is based on the movement of tracers, fluorescent proteins expressed within the suspensor, the occurrence of transmembrane transporters, the absence of a cuticle (which would enforce symplastic transport) around the suspensor and the higher osmotic potential of the suspensor compared with the endosperm (Lee and Yeung 2010). An interesting finding of our study is that plasmodesmata, which occur between the suspensor and endosperm cells at the two-cell stage, are simple and unblocked (Fig. 1). However, they are usually branched and always blocked by electron-dense occlusions at the globular and heart stages (Fig. 2). In all studies reported to date, the structural changes that occur during the conversion of simple plasmodesmata to branched plasmodesmata correlates with a reduction in their conductivity. The transition from simple to branched plasmodesmata reduces their size exclusion limit (e.g. Oparka et al. 1999; Werner et al. 2011). According to Oparka et al. (1999), simple plasmodesmata facilitate macromolecular trafficking, while branched plasmodesmata restrict the nonspecific movement of transport macromolecules. In addition, Rinne and van der Schoot (1998) described how the shoot apical meristem of perennials is symplastically isolated during winter dormancy by plugs deposited on the plasmodesmata, which is very similar to those observed in Crassulaceae. Callose plugs at plasmodesmata have been implicated in the maintenance of dormancy by isolating the meristem from symplastic continuity with surrounding tissues (van der Shoot and Rinne 1999). Van der Shoot and Rinne (1999) suggested that the production of valves on the plasmodesmata appears to be an integral part of the dormancy mechanism. Thus, the results suggest, that in the studied Crassulaceae with plasmodesmata between the endosperm and the suspensor, symplastic connectivity at this cell-cell boundary is still reduced or blocked at a very early stage of embryo development (before the globular stage). However, in future studies, microinjection experiments of fluorescent tracers with different molecular weights to investigate symplastic communication between the suspensor and the endosperm cells are necessary to prove whether these plasmodesmata are blocked or unblocked.

\section{Conclusions}

Ovules are especially interesting in angiosperm systematics and evolution (Endress 2005, 2011; Płachno and Świątek 2009). Future studies should show whether the occurrence of plasmodesmata between the embryo suspensor and the endosperm can be a useful characteristic in discussions about angiosperm systematic and evolution.

It should be emphasized that the presence of plasmodesmata between the embryo suspensor and the endosperm cells suggests that it is a possible route to provide symplastic transport between these organs, at least at a very early stage of embryo development (Fig. 1).

Microinjection of fluorescent tracers with different molecular weights will be used to investigate symplastic communication between the suspensor and the endosperm cells in future tests. Studies of cell signalling help to provide answers to some of the most important questions related to the functions of plasmodesmata, especially that plasmodesmata may be the way in which various molecules 
are transported, e.g. signals, mRNA and viruses. The inclusion of species from other angiosperm families would show whether the occurrence of plasmodesmata between the embryo suspensor and the endosperm may be typical embryological characteristics and if this is useful in discussions about angiosperm systematic and evolution. The result of this study sheds new light on the relationship between the endosperm and the embryo and might be helpful in understanding the dialogue between them.

Acknowledgements We cordially thank the two reviewers for comments which make our manuscript clearer. Also, we very much thank the director of the Botanic Garden of the Jagiellonian University, Prof. Bogdan Zemanek, and the supervisor of Botanic Garden (Chief Gardener), Maria Uzarowicz, for granting us permission to use plants from the garden collections.

Conflicts of interest statement The authors declare that they have no conflict of interest.

Open Access This article is distributed under the terms of the Creative Commons Attribution Noncommercial License which permits any noncommercial use, distribution, and reproduction in any medium, provided the original author(s) and source are credited.

\section{References}

Botha CEJ, Cross RHM (2000) Towards reconciliation of structure with function in plasmodesmata - who is the gatekeeper? Micron 31:713-721

Bruck DK, Walker DB (1985) Cell determination during embryogenesis in Citrus jambhiri. I. Ontogeny of the epidermis. Bot Gaz 146:188-195

Chamberlin MA, Horner HT, Palmer RG (1994) Early endosperm, embryo and ovule development in Glycine $\max (\mathrm{L}$.) Merr. Int J Plant Sci 155:421-436

Chernetskyy M, Weryszko-Chmielewska E (2008) Structure of Kalanchoё pumila Bak. leaves (Crassulaceae DC.). Acta Agrobot 61/2:11-24

Coe GE (1954) Distribution of carbon in ovules of Zephyranthes drummondii. Bot Gaz 115:342-346

Ding B, Itaya A, Woo Y (1999) Plasmodesmata and cell-to-cell communication in plants. Int Rev Cytol 190:251-316

Dute RR, Peterson CM, Rushing AE (1989) Utrastructural changes of the egg apparatus associated with fertilization and proembryo development of soybean, Glycine $\max$ (Fabaceae). Ann Bot 64:123-136

Endress PK (2005) Links between embryology and evolutionary floral morphology. Curr Sci 89:749-754

Endress PK (2011) Angiosperm ovules: diversity, development, evolution. Ann Bot 107:1465-1489

Faulkner C, Maule A (2011) Opportunities and successes in the search for plasmodesmal proteins. Protoplasma 248:27-38. doi:10.1007/ s00709-010-0213-x

Gunning BES, Steer MW (1975) Ultrastructure and the biology of plant cells. Edward Arnold, London, pp 80-82

Han Y-Z, Huang B-Q, Sze-Yong Z, Ming Y (2000) Symplastic communication between the central cell and the egg apparatus cells in the embryo sac of Torenia fournieri Lind. before and during fertilization. Planta 211:158-162
Hyun TK, Uddin MN, Rim Y, Kim JY (2011) Cell-to-cell trafficking of RNA and RNA silencing through plasmodesmata. Protoplasma 248:191-203

Ingram GC (2010) Family life at close quarters: communication and constraint in angiosperm seed development. Protoplasma. doi:10.1007/s00709-010-0184-y

Jackson D (2000) Opening up the communication channels: recent insights into plasmodesmal function. Curr Opin Plant Biol 3:394-399

Johansson M, Walles B (1993) Functional anatomy of the ovule in broad bean, Vicia faba L. II. Ultrastructural development up to early embryogenesis. Int J Plant Sci 154:535-549

Kawashima T, Goldberg RB (2010) The suspensor: not just suspending the embryo. Trends Plant Sci 15:23-30

Kim I, Zambryski PC (2005) Cell-to-cell communication via plasmodesmata during Arabidopsis embryogenesis. Curr Opin Plant Biol 8:593-599

Kim I, Hempel FD, Sha K, Pfluger J, Zambryski PC (2002) Identification of a developmental transition in plasmodesmatal function during embryogenesis in Arabidopsis thaliana. Development 129:1261-1272

Kim I, Cho E, Crawford K, Hempel FD, Zambryski PC (2005) Cellto-cell movement of GFP during embryogenesis and early seedling development in Arabidopsis. Proc Natl Acad Sci U S A 102:2227-2231

Kozieradzka-Kiszkurno M, Bohdanowicz J (2006) Cytochemistry of the embryo suspensor in Sedum. Acta Biol Cracov Ser Bot 48:67-72

Kozieradzka-Kiszkurno M, Świerczyńska J, Bohdanowicz J (2010) Embryogenesis in Sedum acre L.: structural and immunocytochemical aspects of suspensor development. Protoplasma 248:775-784. doi:10.1007/s00709-010-0248-z

Kozieradzka-Kiszkurno M, Płachno BJ, Bohdanowicz J (2011a) Are unusual plasmodesmata in the embryo-suspensor restricted to species from the genus Sedum among Crassulaceae? Flora 206:684-690. doi:10.1016/j.flora.2010.11.017

Kozieradzka-Kiszkurno M, Płachno BJ, Bohdanowicz J (2011b) New data about the suspensor of succulent angiosperms: ultrastructure and cytochemical study of the embryo-suspensor of Sempervivum arachnoideum L. and Jovibarba sobolifera (Sims) Opiz. Protoplasma. doi:10.1007/s00709-011-0297-y

Kurczyńska E (2008) Symplasmic communication: terminology, fluorochromes and Arabidopsis thaliana embryogenesis. Postepy Biol Komorki 35:31-43

Lee YI, Yeung EC (2010) The osmotic property and fluorescent tracer movement of developing orchid embryos of Phaius tankervilliae (Aiton) Bl. Sex Plant Reprod 23:337-341. doi:10.1007/s00497010-0143-y

Lee YI, Yeung EC, Lee N, Chung MC (2006) Embryo development in the lady's slipper orchid, Paphiopedilum delenatii, with emphasis on the ultrastructure of the suspensor. Ann Bot 98:1311-1319

Maheshwari P (1950) An introduction to the embryology of angiosperms. McGraw-Hill, New York

Mansfield SG, Briarty LG (1991) Early embryogenesis in Arabidopsis thaliana. II. The developing embryo. Can J Bot 69:461-476

Natesh S, Rau MA (1984) The embryo. In: Johri BM (ed) Embryology of angiosperms. Springer Verlag, Berlin, pp 377-443

Niehl A, Heinlein M (2011) Cellular pathways for viral transport through plasmodesmata. Protoplasma 248:75-99

Oparka KJ (2005) Annual plant reviews. Plasmodesmata. Oxford, Blackwell

Oparka KJ, Roberts AG, Boevink P, Santa Cruz S, Ian R, Pradel KS, Imlau A, Kotlizky G, Sauer N, Epel B (1999) Simple, but not branched, plasmodesmata allow the nonspecific trafficking of proteins in developing tobacco leaves. Cell 97:743-754 
Pfluger J, Zambryski PC (2001) Cell growth: the power of symplasmic isolation. Curr Biol 11:436-439

Płachno BJ, Światek P (2009) Functional anatomy of the ovule in Genlisea with remarks on ovule evolution in Lentibulariaceae. Protoplasma 236:39-48. doi:10.1007/s00709-009-0045-8

Raghavan V (1997) Experimental embryogenesis in vascular plants. Academic, New York

Raghavan V (2006) Life and times of the suspensor-cell signaling between the embryo and suspensor. In: Raghavan V (ed) Double fertilization. Springer, Berlin-Heidelberg, pp 81-100

Rinne PIH, van der Schoot C (1998) Symplasmic fields in the tunica of the shoot apical meristem coordinate morphogenetic events. Development 125:1477-1485

Rodkiewicz B, Fyk B, Szczuka E (1994) Chlorophyll and cutin in early embryogenesis in Capsella, Arabidopsis, and Stellaria investigated by fluorescence microscopy. Sex Plant Reprod 7:287-289

Sangduen N, Kreitner GL, Sorensen EL (1983) Light and electron microscopy of embryo development in perennial and annual Medicago species. Can J Bot 61:837-849

Shamrov II (2000) Translocation pathways for metabolites in developing ovules of Gentiana cruciata L., Gymnadenia conopsea (L.) R. Br., Gagea stipitata Merklin and Luzula pedemontana Boiss. et Reut. Acta Biol Cracov Ser Bot 42(1):61-77

Schwartz BW, Vernon DA, Meinke DW (1997) Development of the suspensor: differentiation, communication, and programmed cell death during plant embryogenesis. In: Larkins BA, Vasil IK (eds) Cellular and molecular biology of plant seed development, vol 4, Advances in cellular and molecular biology of plants. Kluwer, The Netherlands, pp 53-72

Skubatz H, Kunkel DD (1999) Further studies of the glandular tissue of the Sauromatum guttatum (Araceae) appendix. Am J Bot $86: 841-854$

Stadler R, Wright KM, Lauterbach C, Amon G, Gahrtz M, Feuerstein A, Oparka KJ, Sauer N (2005) Expression of GFP-fusions in Arabidopsis companion cells reveals non-specific protein trafficking into sieve elements and identifies a novel post-phloem domain in roots. Plant $\mathrm{J}$ 41:319-331
Tilsner J, Amari K, Torrance L (2011) Plasmodesmata viewed as specialised membrane adhesion sites. Protoplasma 248:39-60

van der Shoot C, Rinne PIH (1999) The symplasmic organization of the shoot apical meristem. In: van Bel AJE, van Kesteren WJP (eds) Plasmodesmata: structure, function, role in cell communication. Springer, Berlin, pp 227-242

Weng ML, Kuong-Huang LL (1998) Comparative anatomy and histochemical study of the seeds of Sedum formosanum N. E. and Sedum morrisonense Hayata. Taiwania 43:307-315

Werner D, Gerlitz N, Stadler R (2011) A dual switch in phloem unloading during ovule development in Arabidopsis. Protoplasma 248:225-235

Weryszko-Chmielewska E, Chernetskyy M (2005) Structure of trichomes from the surface of leaves of some species of Kalanchoë Adans. Acta Biol Cracov Ser Bot 47(2):15-22

Willemse MTM, Bednara J (1979) Polarity during megasporogenesis in Gasteria verrucosa. Phytomorphology 29:156-165

Williams EG, Knox RB, Kaul V, Rouse JL (1984) Post-pollination callose development in ovules of Rhododendron and Ledum (Ericaceae): zygote special wall. J Cell Sci 69:127-135

$\mathrm{Xu}$ X, Jackson D (2010) Lights at the end of the tunnel: new views of plasmodesmal structure and function. Curr Opin Plant Biol 13:684-692

Yeung EC, Meinke DW (1993) Embryogenesis in angiosperms: development of the suspensor. Plant Cell 5:1371-1381

Yeung EC, Zee SY, Ye XL (1996) Embryology of Cymbidium sinense: embryo development. Ann Bot 78:105-110

Zambryski P (2004) Cell-to-cell transport of proteins and fluorescent tracers via plasmodesmata during plant development. J Cell Biol 162/2:165-168

Zambryski P, Crawford K (2000) Plasmodesmata: gatekeepers for cell-to-cell transport of developmental signals in plants. Annu Rev Cell Dev Biol 16:393-421

Zhang ZJ, Zheng GJ (1988) Translocation of uranin within the living ovules of Vanilla. Acta Bot Sin 30:490-493

Zhukova GY (2006) Ultrastructural characteristics of suspensor. In: Batygina TB (ed) Embryology of flowering plants, vol. 2: Seed. Science Publishers, New Hampshire, pp 202-208 